\title{
The occurrence of non-tubal ectopic pregnancies in women with an intrauterine device
}

\author{
C. A. D. Ringrose \\ 836 Professional Building, 10830 Jasper Avenue Edmonton, Alberta, T5J 2B3, Canada
}

Summary. The occurrence of intra-ovarian gestation in 2 women and an abdominal pregnancy in a third, all bearing IUDs, is described.

\section{Introduction}

Ringrose (1967) has established that approximately 1 pregnancy in 8 of those occurring in women with an intrauterine contraceptive device (IUD) will be ectopic, and many other reports have supported this association (Lehfeldt, Tietze \& Gorstein, 1970; Fernandez \& Barbosa, 1976; Rengachary, Fayez \& Jonas, 1977; Saber, 1977; Girard, Behamdouni \& Larose, 1978). It seems possible that an IUD produces tubal dysfunction, resulting in faulty egg pick-up, altered tubal transport time, or both. Lehfeldt et al. (1970) suggested that more fertilizations per year occur in women with IUDs than in a control group of fertile women and there would therefore be relatively more tubal, ovarian and abdominal pregnancies in the women with IUDs because persisting intrauterine pregnancies are discouraged.

The incidence of abdominal pregnancies is reported as being between 1 in 1372 and 1 in 7931 deliveries, depending on the population surveyed (Skinner \& Koelmeyer, 1976; Strafford \& Ragon, 1977), but these figures would encompass cases starting as ovarian or tubal implantation as well as those associated with ectopic endometrium. Hertig (1951) has estimated that the incidence of ovarian pregnancy (in a population not using the IUD for contraception) is about 1 in 25000 pregnancies, i.e. $0.7-1 \%$ of all ectopic gestations. However, Rengachary et al. (1977) have pointed out that the real incidence may be higher than this because ovarian pregnancies can be missed unless bleeding follicles are serially sectioned.

During a special study of ectopic pregnancies in women, 3 unequivocal cases of non-tubal ectopic implantation were found and they are described in the present report.

\section{Observations}

The patients were women referred to the author at the Misericordia Hospital, Edmonton.

\section{Patient $A$}

Mrs A.B. aged 38 years and para 4, entered hospital because of faintness and pelvic pain which had lasted for 2 days. Her last period was 5 weeks earlier. The patient had had a Lippes Loop installed $1 \frac{1}{2}$ years before this admission. Examination revealed tenderness in the right adnexal area and colpotomy and subsequent laparotomy suggested active bleeding from a cystic corpus luteum in the right ovary. The Fallopian tubes appeared normal. At operation the involved portion of the ovary was resected and prepared for histological examination. There was a 3-week-old corpus luteum in association with an ovarian gestation. The embryonic component was rudimentary. The development of the villi and stromal elements was consistent with a period of 21 days after fertilization. The patient recovered normally and subsequently employed alternative contraception. Her menstrual cycles remained regular. 


\section{Patient $B$}

Mrs C.V., aged 26 years and para 1, entered hospital with pelvic pain, dizziness and sporadic bleeding lasting for 10 days. A Dalkon shield had been inserted 1 year earlier. Her last menstrual period had been 6 weeks before admission and a left adnexal mass had been present for 1 week. Laparotomy revealed a haemorrhagic mass in the place of the left ovary. The Fallopian tubes appeared normal. The involved gonad was removed and examined microscopically. A 4-week-old corpus luteum was present with an associated 4-week embryo and trophoblastic elements. Recovery of the patient was uneventful and she now uses oral contraceptives.

\section{Patient C}

Miss D.B., para 0, aged 21 years and fitted with a small loop for 10 months, entered hospital because of pelvic pain during intercourse for the preceding 2 weeks. She had faintness on one occasion 1 week before admission. Her last menstrual period had occurred 40 days earlier. Examination revealed a tender mass in the cul-de-sac area that was actively bleeding at the time of subsequent laparotomy. The ovaries were adherent in the area. Both Fallopian tubes appeared normal. The tissue mass was removed and the area plicated with purse-string sutures to control blood loss. Histological assessment of the excised tissue indicated that it was placental tissue consistent in development with 26 days post-fertilization. No embryo was found. Recovery of the patient was uneventful. Colon $\mathrm{X}$-ray 3 weeks later was normal.

\section{Discussion}

It is clear that the occurrence of non-tubal ectopic pregnancy in Patient $\mathrm{C}$ was due to a failure of the fimbria to pick up the ovulated egg. The site of fertilization in this patient could have been abdominal, or intra-follicular. The histological sections of the ovaries of Patients A and B showed that the gestation was intra-ovarian and fertilization in these women had almost certainly been intra-follicular. The occurrence of this phenomenon has not been directly shown in women but is not unknown in mammals, having been reported for the insectivores, Hemicentetes and Setifer (Strauss, 1938, 1939).

It is suggested that closer examination of the bleeding ovaries of women with an IUD would indicate a much higher incidence of ovarian gestations than at present suspected.

\section{References}

Fernandex, C. \& Barbosa, J.J. (1976) Primary ovarian pregnancy with an intrauterine device. Obstet. Gynec. 47, 9-11.

Girard, Y., Behamdouni, M. \& Larose, J. (1978) Primary ovarian pregnancy with a device. Obstet. Gynec, 51, 52-55.

Hertig, A.T. (1951) Primary ovarian pregnancy. Am. J. Obstet. Gynec. 62, 926-930.

Lehfeldt, H., Tietze, C. \& Gorstein, F. (1970) Ovarian pregnancy and the intrauterine device. Am.J. Obstet. Gynec. 108, 1005-1009.

Rengachary, D., Fayez, J. \& Jonas, H. (1977) Ovarian pregnancy. Obstet. Gynec. 49, 76-78.

Ringrose, C.A.D. (1967) The occurrence of pregnancy despite the presence of a Lippes Loop. Can. Med. Ass. J. 97, 342-344.

Saber, R.S. (1977) Ovarian pregnancy with an intrauterine device. Post. Grad. Med. 53, 152-155.

Skinner, C.O. \& Koelmeyer, T.D. (1976) Advanced intra-abdominal pregnancy. Aust. J. Surg. 46, 251254.

Strafford, J.C. \& Ragon, W. (1977) Abdominal pregnancy. Obstet. Gynec. 50, 548-552.

Strauss, F. (1938) Die Befruchtung und der Vorgang der Ovulation bei Ericulus aus der Familie der Centetiden. Biomorphosis 1, 281-312.

Strauss, F. (1939) Die Bildung der Corpusluteum bei Centetiden. Biomorphosis 1, 489-544. 